Rakenteiden Mekaniikka (Journal of Structural Mechanics)

Vol. 50, No 2, 2017, pp. 97-113

http://rakenteidenmekaniikka.journal.fi/index

https:/doi.org/10.23998/rm.65309

(C)Author(s) 2017.

Open access under CC BY-SA 4.0 license.

\title{
Numerical analysis of steel columns stabilized by sandwich panels
}

\author{
Zhongcheng $\mathrm{Ma}^{1}$, Jarmo Havula, and Markku Heinisuo
}

Summary. Two different types of finite element models to simulate the steel columns supported by sandwich panels are developed in this paper and validated by the full-scale tests by Hedman-Petursson (2001) at ambient temperature. The bracing forces in self-drilling screws, the effect of connections in horizontal joints, effects of the lateral stiffness of self-drilling screws are studied using the developed FE models. Effect of different configurations of loading eccentricity on the buckling resistances of steel columns supported by sandwich panels are further analyzed in this paper.

Key words: stabilization, buckling resistance, sandwich panels

Received 28 April 2017. Accepted 1 August 2017. Published online 7 August 2017.

\section{Introduction}

Sandwich panels are used as building envelope. They usually comprise two layers of thin steel faces and a thick core layer of lightweight insulation materials. Sandwich panels have long span capability and high insulation standard, and can be used as wall or roof claddings. The four most commonly used insulation materials are the polyurethane foams, polyisocyanurate foams, expanded/extruded polystyrene, and mineral wool based products.

It has been shown in recent projects that considerable savings can be achieved for structural columns and beams if the sandwich panels are used for stabilizing the structures $[2,3,4,6]$. The high in-plane shear stiffness of sandwich panels can increase the resistances of beams and columns against lateral torsional buckling and flexural buckling.

${ }^{1}$ Corresponding author. zhongcheng.ma@hamk.fi 
In this paper, two different types of finite element models to simulate the steel columns supported by sandwich panels will be developed and validated. The stabilization effect of two steel columns supported by sandwich panels with mineral wool (MW) core is further studied using the developed analysis techniques. In addition to the increased buckling resistances, the bracing forces in the screw fasteners and the effect of connection in horizontal joints of sandwich panels are further investigated. The influence of loading configurations due to eccentricity will be also analysed and the corresponding suggestion for testing and FE analysis will be given.

\section{FE models and validation}

\section{Full-scale tests by Hedman-Petursson}

Hedman-Petursson in 2001 [4] conducted five full-scale tests to study the stabilizing effects of sandwich panels on steel column buckling. The tests consist of two types of profiled steel columns with different eccentricities of axial loading. In the first two tests HEA120 steel columns were used. The loading eccentricity was set to $5 \mathrm{~mm}$ (approximately L/1000) for Case A (Test 1) in both y- and z- direction, and $50 \mathrm{~mm}$ in zdirection and $5 \mathrm{~mm}$ in y-direction for Case B (Test 2), respectively. The eccentricity of axial loading applies a constant moment around the strong axis over the column length, and the compressed flange is the top side of the column for Case B.

The test set-up is illustrated in Fig. 1. In these tests, two columns with four sandwich panels were placed horizontally. The length of column is $4.62 \mathrm{~m}$ and the length and width of sandwich panel is $5.0 \mathrm{~m}$ and $1.1 \mathrm{~m}$, respectively. The boundary conditions at the ends of the columns are pinned both around strong and weak axes. The rotations around $\mathrm{x}$-axis in the ends of the column are restrained and warping of cross section in both ends is restrained by the $10 \mathrm{~mm}$-thick welded end plates. The buckling length (without sandwich panels) of the column in weak and strong axis buckling can be considered as $4.62 \mathrm{~m}$. The panel thickness is $150 \mathrm{~mm}$, and nominal thickness of panel face is $0.6 \mathrm{~mm}$. The steel grade of column is S275. The tensile strength properties of the faces were measured [4]. Two self-drilling screws of $5.5 \mathrm{~mm}$ in diameter near the panel corners in each side were used to connect the panel with the upper flange of steel column. The edge distance is $30 \mathrm{~mm}$ in both $\mathrm{y}$ and $\mathrm{z}$ directions. Three rivets were used in each side of panel face in horizontal joints to form a diaphragm.

The ultimate buckling load of the column without restraints is $173 \mathrm{kN}$ according to EN 1993-1-1 [7] based on the buckling length $4.62 \mathrm{~m}$ and on the measured yield strength $300 \mathrm{MPa}$ from the tests. The failure mode is flexural buckling in y-direction (minor axis buckling). When the lateral displacement of column is fully restrained in ydirection the buckling resistance is $393 \mathrm{kN}$ and the calculated ultimate load of column according to EN1993-1-1 [7] is $384 \mathrm{kN}$ (eccentricity $L / 1000=4.62 \mathrm{~mm}$ ) for Case A and $220 \mathrm{kN}$ for Case B (eccentricity $50 \mathrm{~mm}$ ). 


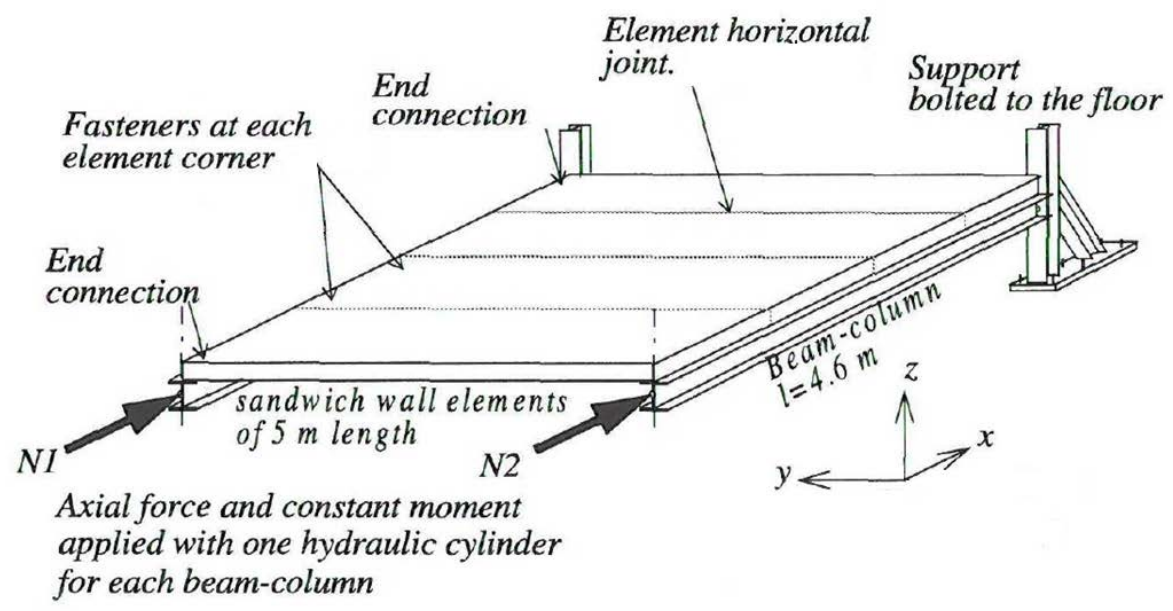

Figure 1. Test setup of full scale tests by Hedman-Petursson [4].

\section{FE models}

Finite element code Ls-Dyna v971 [5] is used for the explicit analyses conducted in this research. The steel columns are modeled using shell elements with Belytschko-Tsay formulation (ELFORM=2). Sandwich panels are modeled using two approaches: Model I using composite shell elements (*PART_COMPOSITE, ELFORM=2) with userdefined multi-layers and laminated shell theory (LAMSHT=1), Model II using shell element for steel facings and solid elements for MW core. Reduced integration solid element is used (ELFORM=1). The glue materials between steel faces and MW core are also modeled using solid elements. The reason for including the glue layer will be described later. General views of these two FE models are illustrated in Fig. 2

The self-drilling screws and rivets are modeled using discrete beam element (beam element with ELFORM=6). Discrete beam element in Ls-Dyna has six degree of freedoms that depict three translational springs and three rotational springs. Three translational spring constants are defined for discrete beam element in the FE model and the rotational restraints are neglected according to the test results by Hedman-Petursson [4]. For FE models using Model II approach for sandwich panels, the discrete beam element is used between the lower face of panel and upper flange of steel column, and the general beam element $(E L F O R M=1)$ is used to connect lower face and upper face in the corresponding screw fastener locations. Fig. 3 illustrates the use of discrete beam elements to simulate the self-drilling screws which connect the sandwich panels and upper flanges of steel columns.

Residual stresses of steel profile are defined according to the measurement by Hedman-Petursson [4] and can be seen in Fig. 4. Geometric imperfections are modelled by eccentricity of $-4.62 \mathrm{~mm}$ (L/1000) in both y- direction and z-direction for Case A. For Case B, initial imperfection of $-4.62 \mathrm{~mm}$ is modelled in y-direction, and the eccentricity in z-direction is $50 \mathrm{~mm}$.

Material models and major material parameters used for the analyses are illustrated in Table 1. The translational stiffness of screws and rivets is based on the study in [4]. 


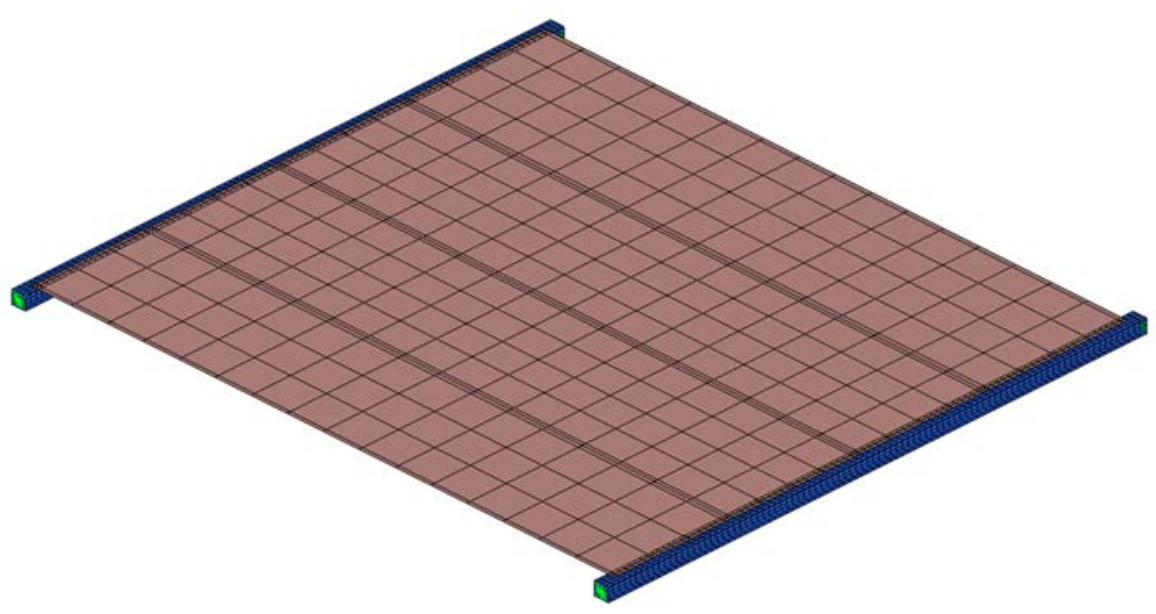

(a) Model I: composite shell elements for sandwich panels

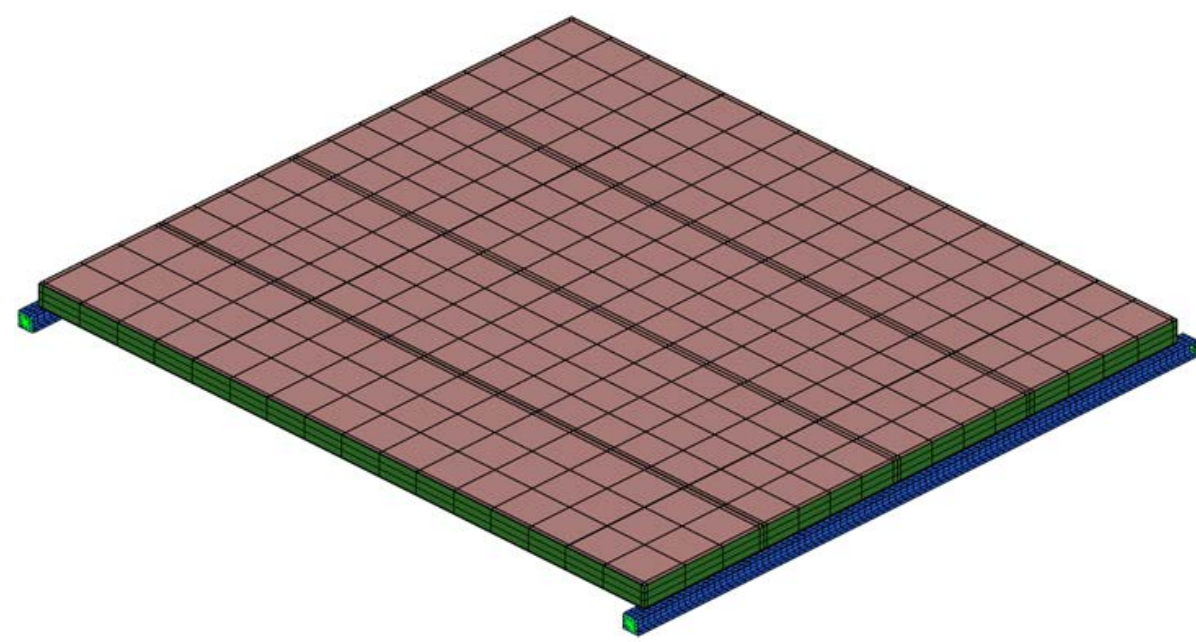

(b) Model II: thin shell elements for steel faces and solid elements for MW core and glue layer

Fig. 2. General views of two FE models used for the following analyses. 


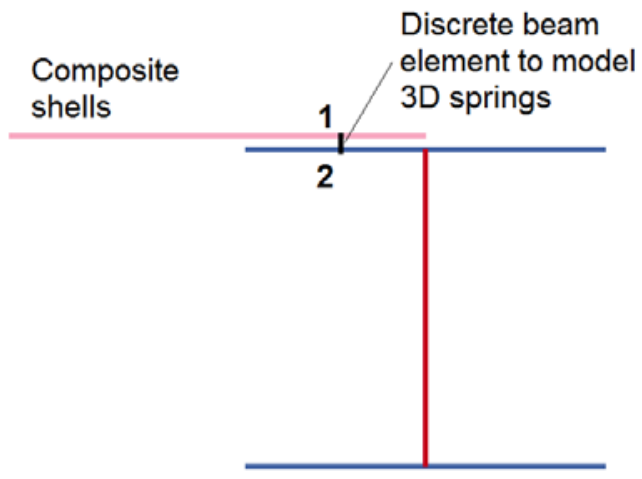

(a) Model I

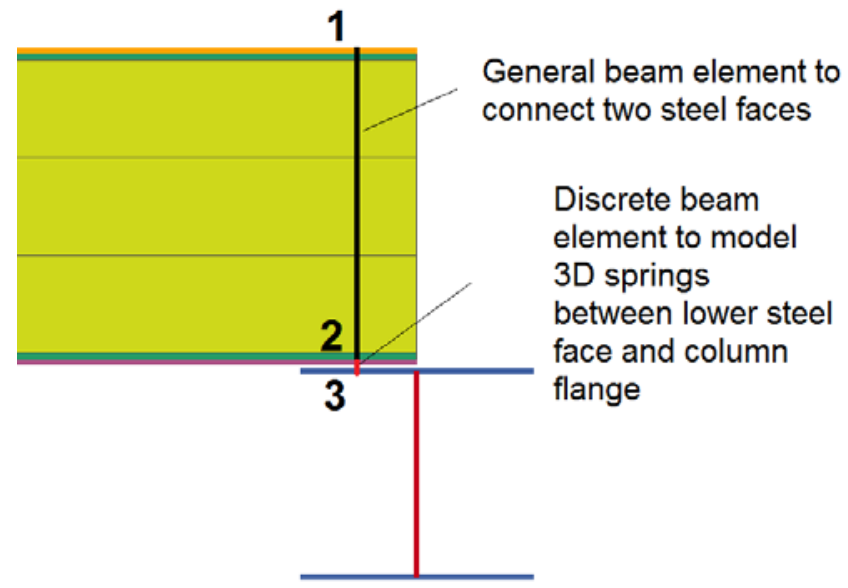

(b) Model II

Fig. 3 Discrete beam elements in modeling the self-drilling screws

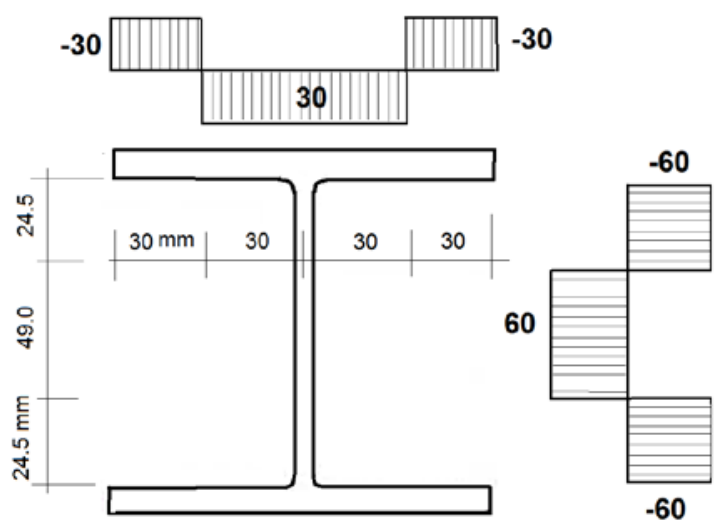

Fig. 4 Residual stresses of steel column used in FE model. Bottom flange has the same stress distribution as upper flange 
Table 1. Material models and major parameters.

\begin{tabular}{|c|c|c|}
\hline Materials & Material Models & Material Parameters \\
\hline Steel columns & $\begin{array}{l}\text { *MAT_Piecewise } \\
\text { _Linear_Plasticity } \\
\text { (MAT24) }\end{array}$ & $\begin{array}{l}\text { Elastic modulus } \mathrm{E}=210 \mathrm{GPa} \\
\text { Poisson's ratio } \gamma=0.3 \\
\text { Yield stress } \mathrm{f}_{\mathrm{y}}=300 \mathrm{MPa} \\
\text { Tangent modulus after yielding } \mathrm{E}_{\tan }=324 \mathrm{MPa} \\
\text { Failure strain } \varepsilon_{\text {fail }}=0.15\end{array}$ \\
\hline Steel facing & $\begin{array}{l}\text { *MAT_Piecewise } \\
\text { _Linear_Plasticity } \\
\text { (MAT24) }\end{array}$ & $\begin{array}{l}\text { Elastic modulus } \mathrm{E}=200 \mathrm{GPa} \\
\text { Poisson's ratio } \gamma=0.3 ; \\
\text { Yield stress } \mathrm{f}_{\mathrm{y}}=390 \mathrm{MPa} \text {; } \\
\text { Tangent modulus after yielding } \mathrm{E}_{\mathrm{tan}}=1305 \mathrm{MPa} \text {; } \\
\text { Failure strain } \varepsilon_{\mathrm{fail}}=0.15 ;\end{array}$ \\
\hline Mineral wool & $\begin{array}{l}\text { *MAT_Elastic } \\
\text { (MAT1) }\end{array}$ & $\begin{array}{l}\text { Elastic modulus E=19.2 MPa; } \\
\text { Poisson's ratio } \gamma=0.3 \\
\text { Mass density } \rho=125 \mathrm{~kg} / \mathrm{m}^{3} \text {; }\end{array}$ \\
\hline Glue & $\begin{array}{l}\text { *MAT_Modified } \\
\text { _Johnson_Cook }\end{array}$ & $\begin{array}{l}\text { Elastic modulus } \mathrm{E}=1000 \mathrm{MPa} \\
\text { Yield stress } \mathrm{A}=200 \mathrm{MPa} \text {; } \\
\text { Melt temperature } \mathrm{T}_{\text {melt }}=200^{\circ} \mathrm{C} \text {; }\end{array}$ \\
\hline $\begin{array}{l}\text { Self-drilling } \\
\text { screws }\end{array}$ & $\begin{array}{l}\text { *MAT_Linear } \\
\text { _Elastic_Discrete } \\
\text { _Beam } \\
\text { (MAT66) }\end{array}$ & $\begin{array}{l}\text { Translational stiffness } T K x=1000 \mathrm{~N} / \mathrm{mm} \text {; } \\
\text { Translational stiffness } \mathrm{TKy}=1000 \mathrm{~N} / \mathrm{mm} \text {; } \\
\text { Translational stiffness } \mathrm{TKz}=1000 \mathrm{~N} / \mathrm{mm} \text {; }\end{array}$ \\
\hline Rivets & $\begin{array}{l}\text { *MAT_Linear } \\
\text { _Elastic_Discrete } \\
\text { _Beam } \\
\text { (MAT66) }\end{array}$ & $\begin{array}{l}\text { Translational stiffness } T K x=1820 \mathrm{~N} / \mathrm{mm} \text {; } \\
\text { Translational stiffness } \mathrm{TKy}=1820 \mathrm{~N} / \mathrm{mm} \text {; } \\
\text { Translational stiffness TKz=1820 N/mm; }\end{array}$ \\
\hline
\end{tabular}

\section{Model validation}

Fig. 5 shows the comparison between the FE analysis results using Model I approach for sandwich panels and test results of HEA120 under axial loading (Test 1\&2) by Hedman-Petursson [4]. The abscissa is the flexural displacement in mid-point of columns in z-direction. The ordinate is axial load in x-direction. The coordinate system can be seen in Fig. 1. Fig. 6 shows the comparison between FE analysis results using 
Model II approach and Test 1 \& 2. In these figures and following tables, column-R denotes the right steel column shown in Fig. 1 and column-L denotes the left column. It can be seen that there is good agreement between the FE analyses and test measurement for the models using both Model I and II approaches.

Table 2 summarizes the buckling loads and failure modes from test results and FE analyses. In the table, FB-z denotes flexural buckling in z-direction in the plane of column web (around strong axis) and LTD denotes lateral torsional deformation. The predicted buckling load based on the Model I is 7\% lower and that based on the Model II is $7 \%$ higher compared to the test results. The predicted failure modes are similar to those in the testing report. However, from the FE analysis, lateral torsional deformation of steel column can be observed in addition to the primary flexural deformation in $\mathrm{z}$ direction when buckling load is reached for Case A. Fig. 7 shows the pictures of deformation contour at maximum buckling loads for Case A and Case B. From Fig. 7a it can be seen that the bending deformation in z-direction is not uniform for the crosssection in the middle of column: the left portion of the upper and lower flanges has more deformation than the right portion so that the z-axis of cross section rotates which indicates a lateral-torsional deformation. This is mainly caused by the original eccentricities $(-4.62 \mathrm{~mm})$ in $\mathrm{y}$-direction and z-direction in FE model for Case A. For Case B, from Fig. $7 \mathrm{~b}$ it can be seen that the deformation in z-direction is relatively uniform for the whole cross-section in the middle of the column which indicates a flexural buckling mode.

Table 2. Buckling loads and failure modes of tests by Hedman-Petursson and FE analyses.

\begin{tabular}{|c|c|c|c|c|c|c|c|c|}
\hline \multirow[t]{2}{*}{ Tests } & \multirow{2}{*}{$\begin{array}{l}\text { Tested } \\
\text { buckling } \\
\text { load (kN) }\end{array}$} & \multirow{2}{*}{$\begin{array}{l}\text { Buckling } \\
\text { failure } \\
\text { mode } \\
\text { from tests }\end{array}$} & \multicolumn{3}{|c|}{$\begin{array}{l}\text { Buckling loads by FE Model I } \\
(\mathrm{kN})\end{array}$} & \multicolumn{3}{|c|}{$\begin{array}{l}\text { Buckling loads by FE Model II } \\
(\mathrm{kN})\end{array}$} \\
\hline & & & $\begin{array}{l}\text { Column- } \\
\text { R }\end{array}$ & $\begin{array}{l}\text { Column- } \\
\text { L }\end{array}$ & $\begin{array}{l}\text { Failure } \\
\text { mode }\end{array}$ & $\begin{array}{l}\text { Column- } \\
\text { R }\end{array}$ & $\begin{array}{l}\text { Column } \\
\text { L }\end{array}$ & $\begin{array}{l}\text { Failure } \\
\text { mode }\end{array}$ \\
\hline Test-1 & 412.3 & FB-z & 392.0 & 384.0 & FB-z+LTD & 428.0 & 410.0 & FB-z+LTD \\
\hline Test-2 & 221.8 & FB-z & 223.0 & 225.0 & FB-Z & 236.0 & 237.0 & FB-z \\
\hline
\end{tabular}

Note: LTD denotes lateral-torsional deformation.

Both these two FE modeling approaches are validated at ambient temperatures. However, only Model II can be extended to simulate the sandwich panels at elevated temperatures. The reason is that, in addition to the material degradation at elevated temperatures, the internal steel face will experiment high temperatures and delamination between internal steel face and MW core may occur at $130-350{ }^{\circ} \mathrm{C}$ if the thermal setting adhesives such as polyurethane are used [1]. This kind of adhesives are very common in practice. In order to simulate the delamination between internal steel face and MW core at elevated temperatures, a thin layer of solid elements were included in the FE model for glue and modified Johnson Cook material model (MAT107) can be used for glue 


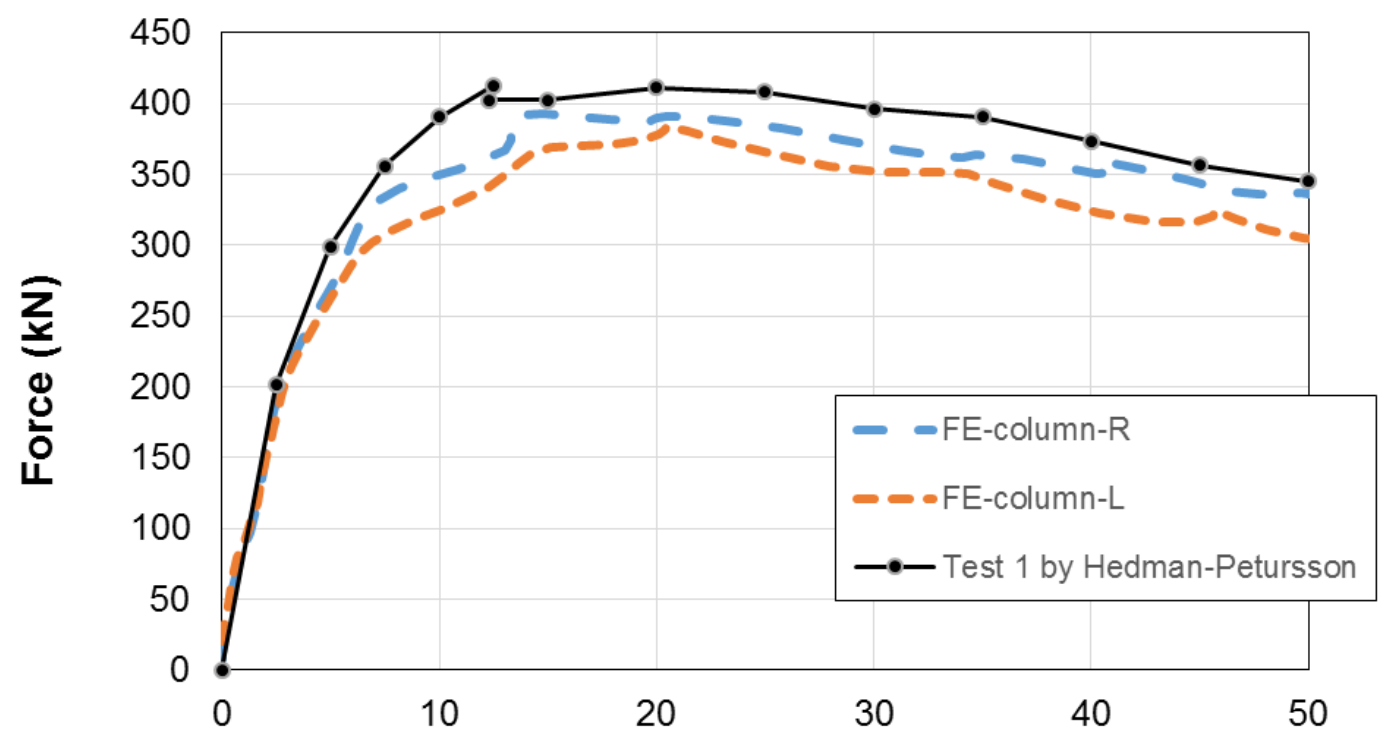

Flexural displacement at mid-span in z-direction ( $\mathrm{mm})$

(a) Full scale Test 1 by Hedman-Petursson (Case A)

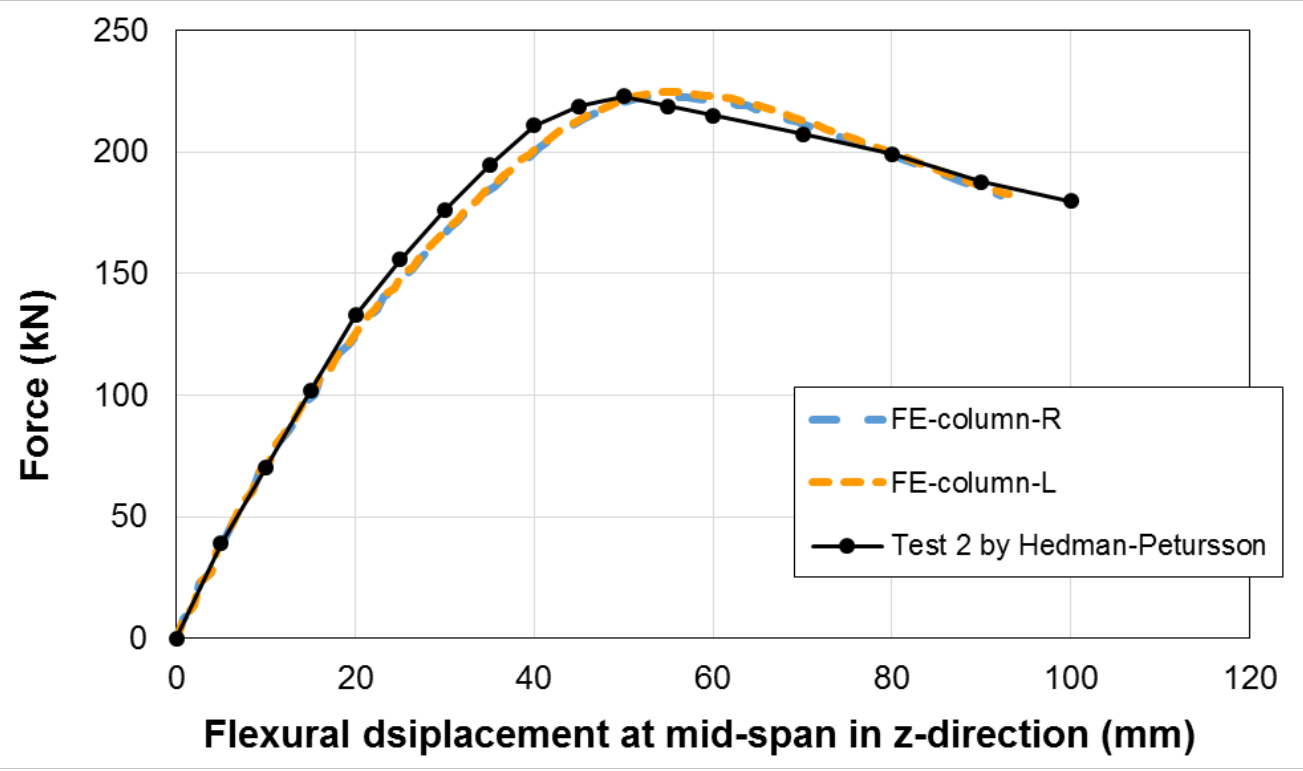

(b) Full scale Test 2 by Hedman-Petursson (Case B)

Fig. 5 Comparison between FE analysis using Model I approach and full scale tests by HedmanPetursson. Composite shell elements are used in modeling the sandwich panels. 


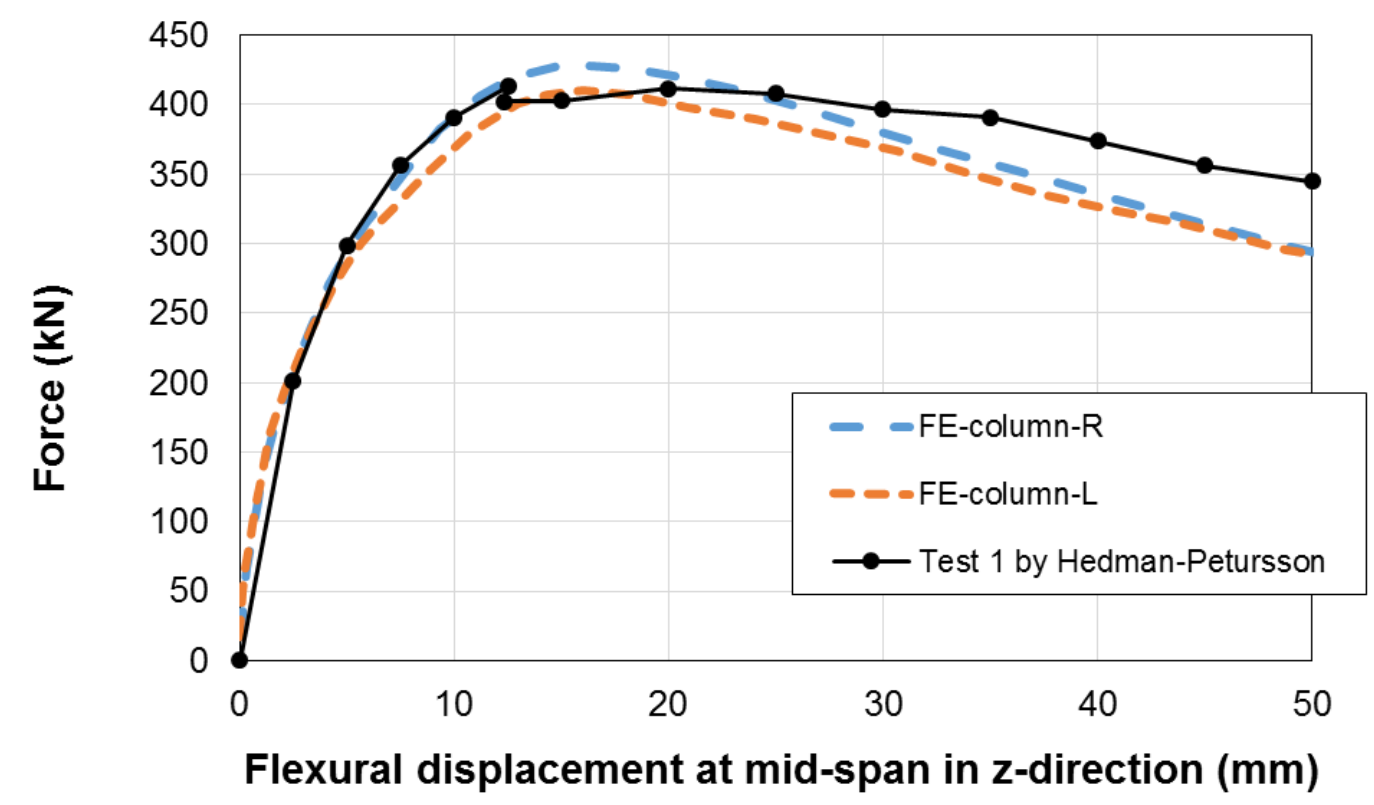

(a) Full scale Test 1 by Hedman-Petursson (Case A)

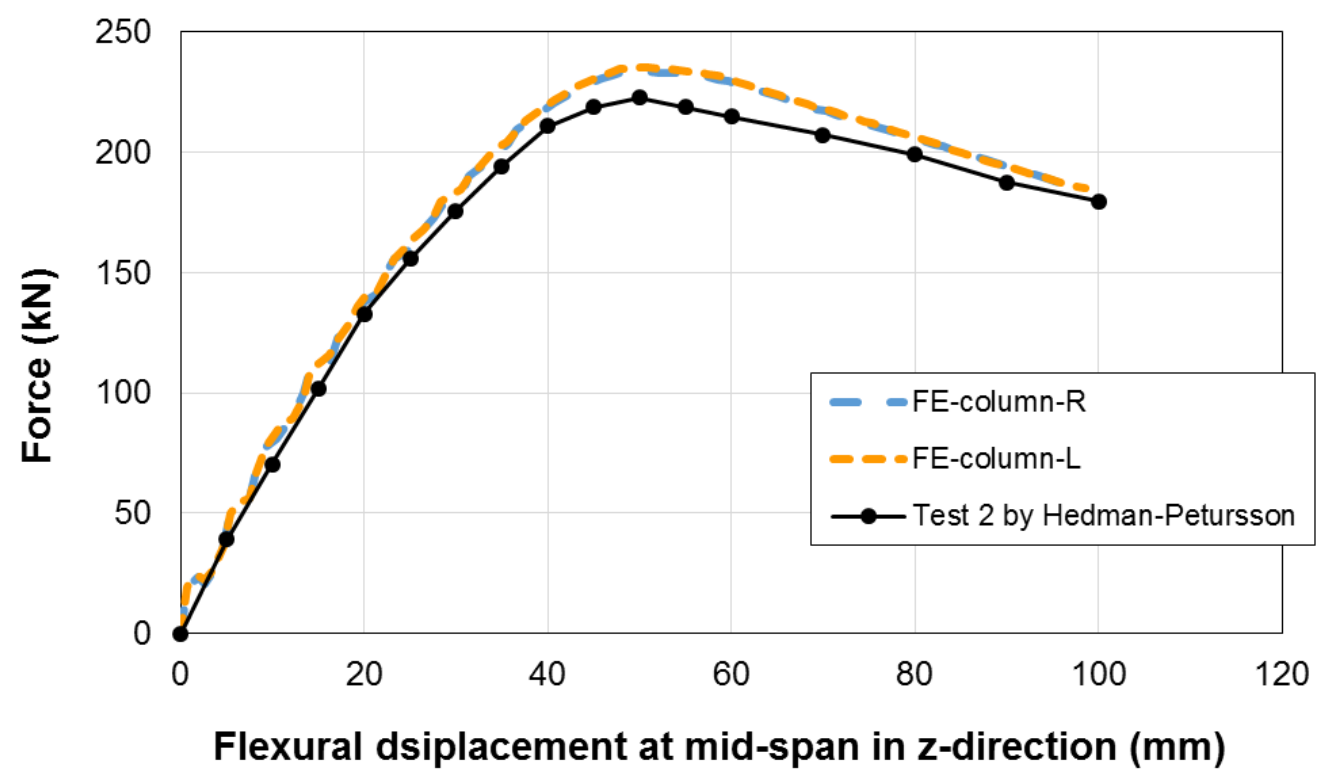

(b) Full scale Test 2 by Hedman-Petursson (Case B)

Fig. 6 Comparison between FE analysis using Model II approach and full scale tests by Hedman-Petursson. Shell elements are used in modeling the steel faces of sandwich panels and solid elements are used in modeling the glue and MW core. 


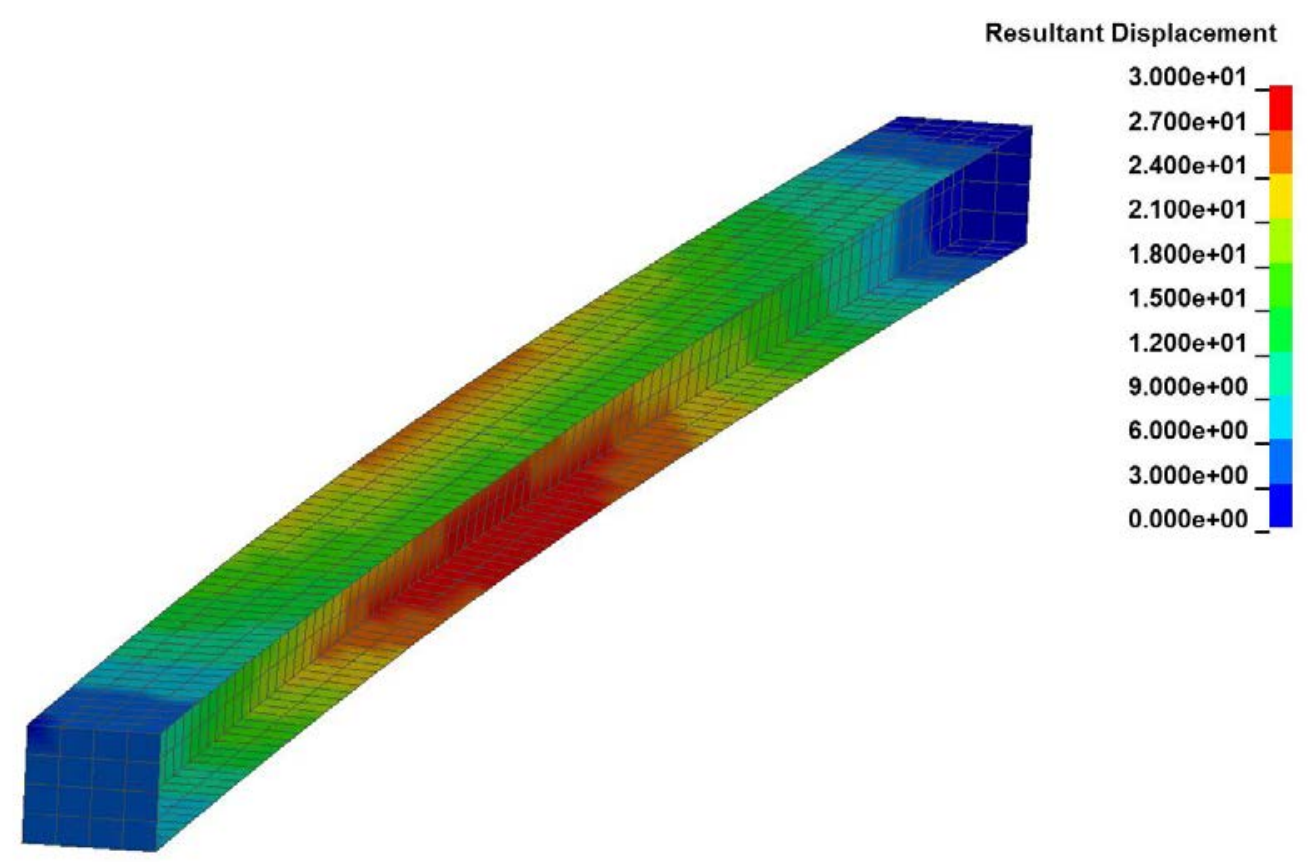

(a) Case A

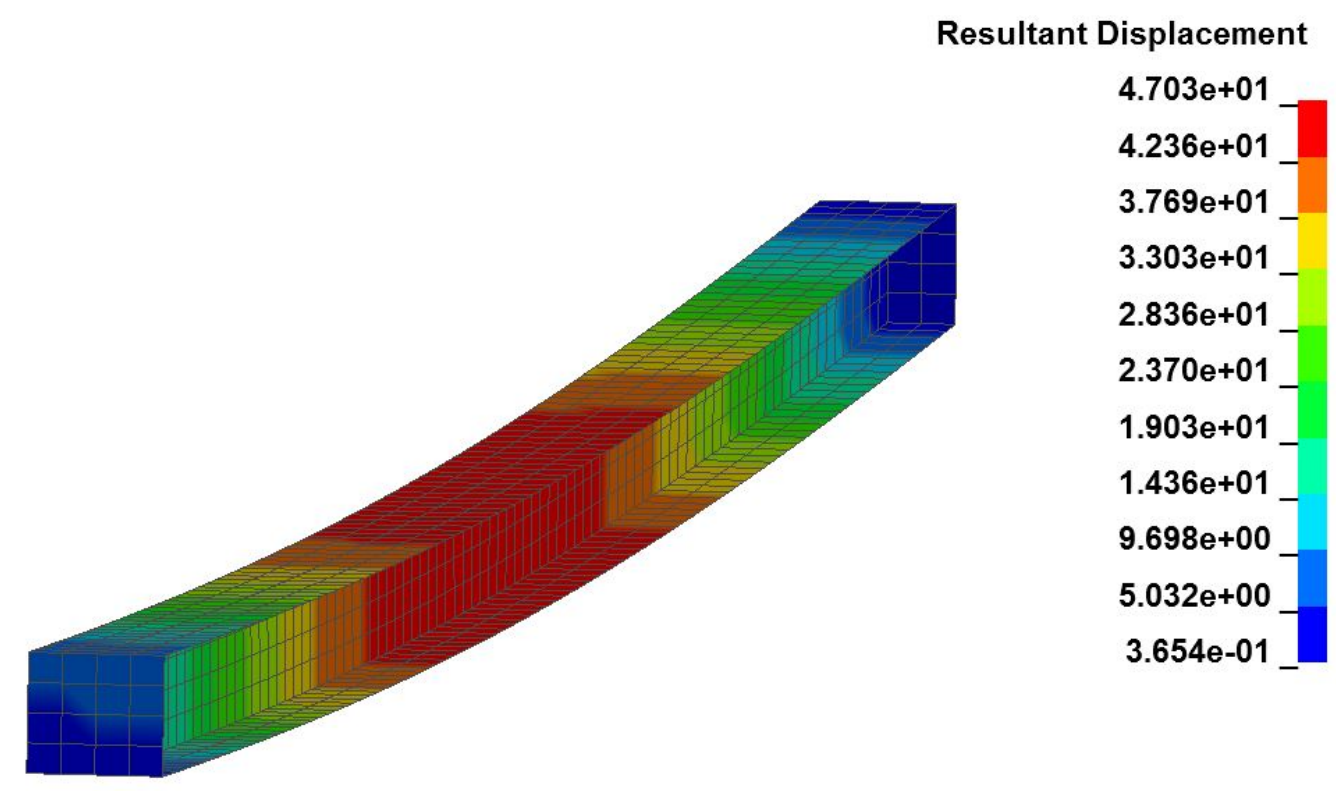

(b) Case B

Fig. 7 Deformation contours of steel column at maximum buckling loads. The resultant displacement is in $\mathrm{mm}$. 
layer. In this material model, the melting temperature can be defined and elements will be eroded when the temperature reaches the melting temperature. The study of steel columns supported by sandwich panels at elevated temperatures will be carried out and reported later.

\section{Further investigations at ambient temperature}

\section{Bracing forces in self-drilling screws}

The bracing forces of two self-drilling screws in each end of right column using Model II are illustrated in Fig. 8. The development of shear forces in y-direction (longitudinal direction of sandwich panel) vs z-displacement of middle point of steel column is shown. SDS-R-1 denotes the first self-drilling screw near the loading end of right column, SDS-R-8 denotes the last screw along right column length near the opposite end. It can be seen that the shear forces in the screws in Case A increase during the loading until buckling (displacement about $15 \mathrm{~mm}$ ) and continue to increase after buckling. The maximum shear force in y-direction is $6.1 \mathrm{kN}$ corresponding to the buckling load of column. If the resistance of $2.0 \mathrm{kN}$ is assumed for a single screw, this indicates that three self-drilling screws are needed in the end connections in the design of utilizing the stabilization by sandwich panels. The maximum connection force for screws in the middle is $2.6 \mathrm{kN}$ and hence two screws are needed in the middle connections. In the full scale test by Hedman-Petursson [4], three screws were used in both end connections for anchoring the sandwich panels, and one screw was used in the middle connections. The shear forces along the column length (x-direction) are $0.24 \mathrm{kN}$ for both end connections at maximum buckling loads, which is small in comparison with the shear forces in y-direction.

Fig. 9 shows the shear forces of self-drilling screws in y-direction under axial loading and constant moment (Case B). It can be seen that the maximum shear force in the screw fasteners is $2.4 \mathrm{kN}$ when the ultimate load is reached, and continues to increase to $3.0 \mathrm{kN}$ after column buckling until the mid-displacement of column reaches $70 \mathrm{~mm}$. It should be noted that the small oscillations along the curves are due to the artificial dynamic effect by explicit solver. If the loading speed is reduced and total analysis time is prolonged, the curves will be smoother. However, this is not favored for the current computer used for the analysis.

Fig.10 shows the displacements of columns and panel at the locations of screw connectors at the time of ultimate buckling loads, for the first panel near loading end. The first value in the array is the displacement of lower face of sandwich panel in $y$ direction at the location of screw, and the second value is the corresponding displacement of upper flange of steel column. The relative displacement between lower face of the panel and upper flange of column at location of screw connector represents the displacement of connector and the shear force of screw connector can be calculated based on it. From the figures it can be seen that the displacements of sandwich panel at screw locations are close to each other, and this indicates a very small in-plane deformation of sandwich panel. The relative displacements in the screws near column ends are larger than those in the middle locations, and therefore the shear forces are larger as well. 


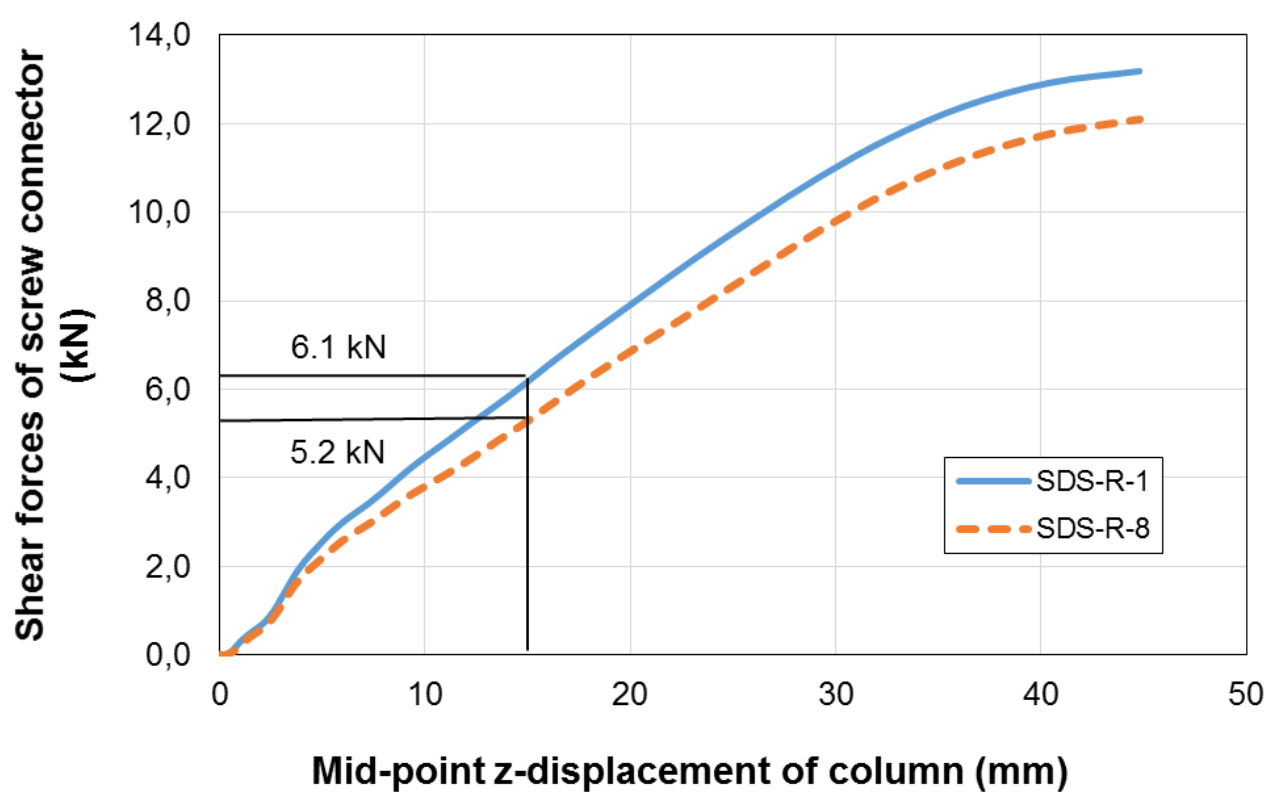

Fig. 8 Shear forces of self-drilling screws during the axial loading (Case A). SDS-R-1 and SDSR-8 denote two end screws connecting the sandwich panels along the right column in the analyzed structure.

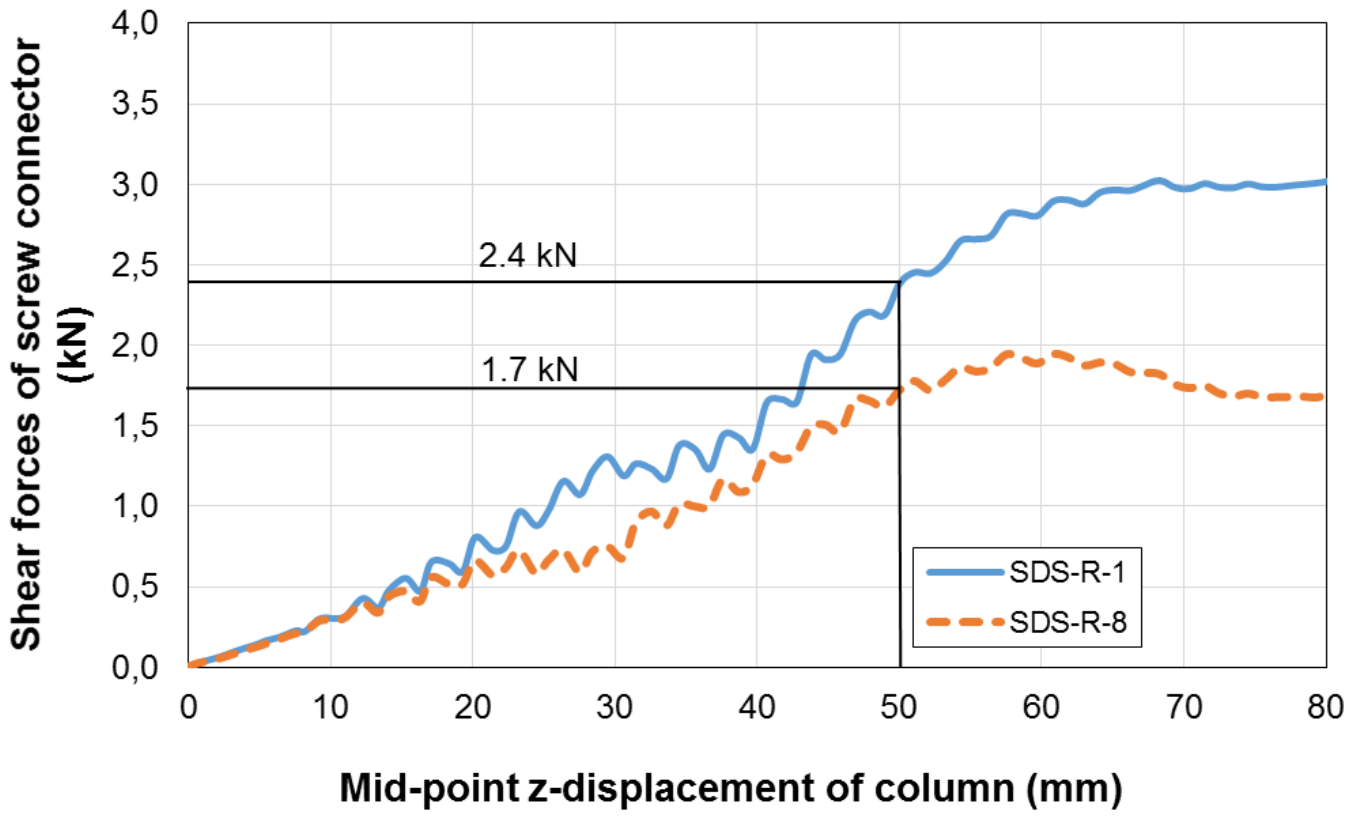

Fig. 9 Shear forces of self-drilling screws during the axial loading and constant moment (Case B). 


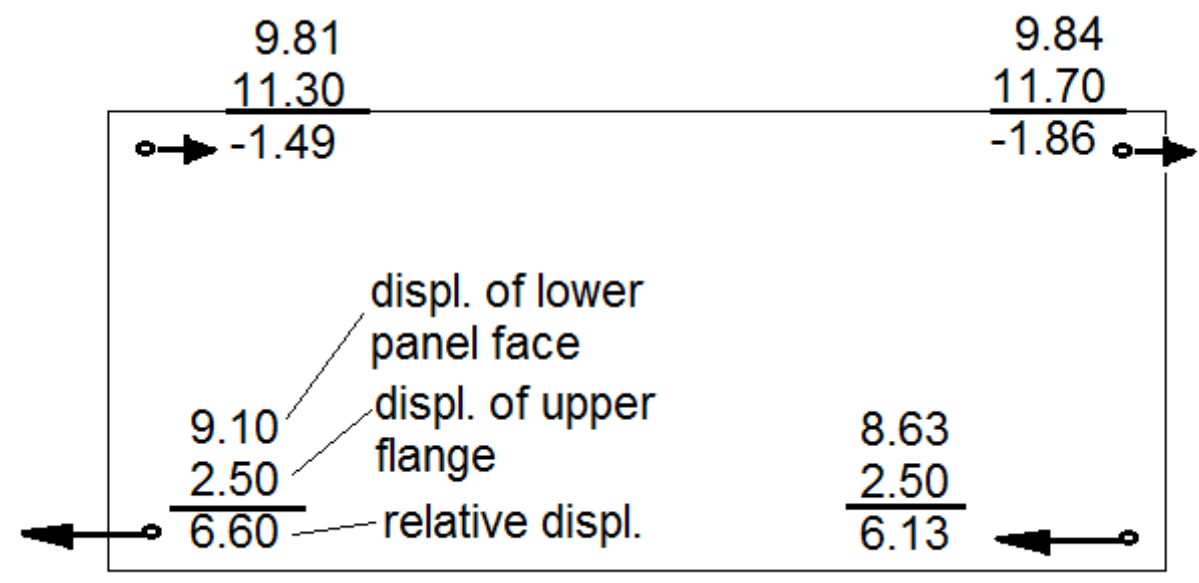

(a) Case A using Method II

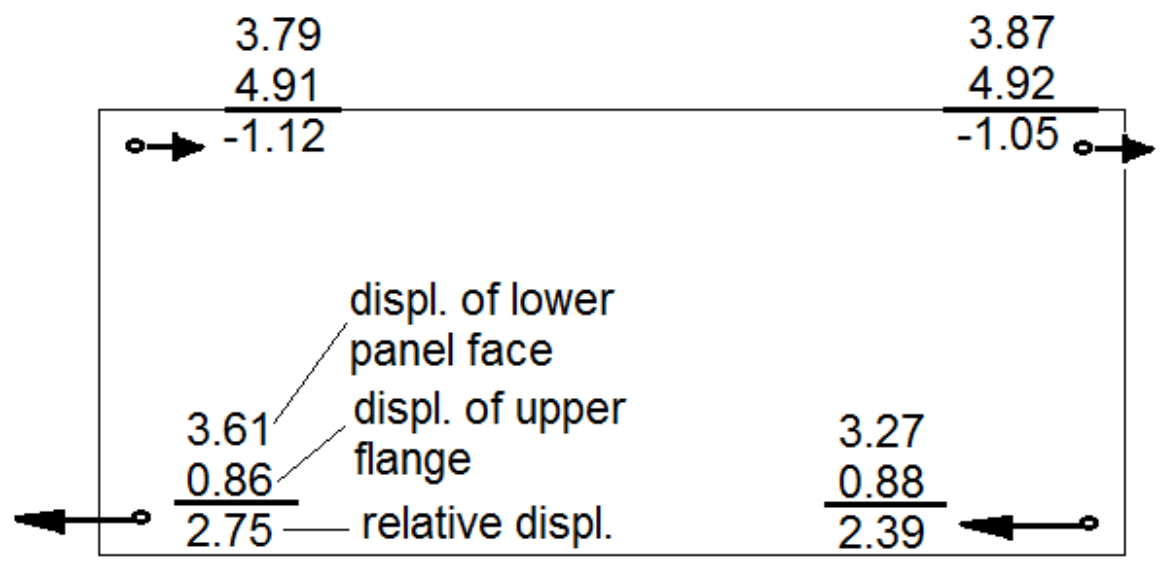

(b) Case B using Method II

Fig. 10 Displacements of a sandwich panel and steel columns at screw locations at ultimate loads.

\section{Effect of connections in horizontal joints}

Sandwich panels are normally connected to the supporting structure at the transverse edges only. They usually do not have connections at the longitudinal/horizontal edges. This is common practice, especially for wall panels [3]. Each panel acts as an individual element. Table 3 compares the analysis results of buckling resistance for the same structures with and without rivet connections in horizontal joints, using FE Model II. It can be seen that the contribution of connected horizontal joints is around $8 \%$ for axial loading case (Case A) and less than 1\% for beam-column case with eccentricity of 50 $\mathrm{mm}$ (Case B). 
Table 3. Effect of connection in horizontal joints of sandwich panels.

\begin{tabular}{l|l|l|c}
\hline Cases & $\begin{array}{l}\text { Buckling loads for } \\
\text { sandwich panels } \\
\text { connected by 3+3 } \\
\text { rivets in each } \\
\text { longitudinal joints } \\
(\mathrm{kN})\end{array}$ & $\begin{array}{l}\text { Buckling loads for } \\
\text { sandwich panels } \\
\text { not connected in } \\
\text { longitudinal joints }\end{array}$ & \\
\hline Case-A & 428 & & \\
\hline Case-B & 236 & 234 & 0.4 \\
\hline
\end{tabular}

\section{Effect of lateral stiffness of self-drilling screws}

According to Eq. 25 of ECCS/CIB [3], the connection stiffness of $5.5 \mathrm{~mm}$ self-drilling screw for a $0.52 \mathrm{~mm}$ core thickness of S350 steel sheet, the stiffness of internal steel sheet (hole elongation) is around $3100 \mathrm{~N} / \mathrm{mm}$. This value is much higher than the value proposed by Hedman-Petursson [4] and used in the analyses. It should be noted that ECCS recommendations require larger edge distance for the screw connectors than the value used in the full scale tests. The recommended stiffness given in ECCS/CIB [3] results in a buckling load of $470 \mathrm{kN}$, which is $10 \%$ higher than the load based on the stiffness of $1000 \mathrm{~N} / \mathrm{mm}$. The failure mode is combined flexural buckling in z-direction (major axis buckling) + lateral-torsional deformation.

A further FE analysis was made for the steel column without sandwich panels, but instead fully restrained in y-direction along the center line of web. A flexural buckling load of $437 \mathrm{kN}$ (in z- direction) was obtained, which is less than the above value of 470 $\mathrm{kN}$. This indicates that a composite action (restraint in $\mathrm{xz}$ plane) may exist between sandwich panels and steel column when the lateral stiffness of fasteners increases.

\section{Stabilization effect by sandwich panels}

Further FE analyses were conducted to obtain the buckling loads of single column around z-axis and y-axis without support by sandwich panels. Analysis results show that the ultimate buckling load of the column without restraints is around $184 \mathrm{kN}$ and the failure mode is flexural buckling in y-direction (minor axis buckling). When the lateral displacement of column is fully restrained in y-direction along the mid-line of web, the ultimate buckling load in z-direction (major axis buckling) is $437 \mathrm{kN}$ according to the FE analysis. The calculated ultimate load of column according to EN1993-1-1 [7] is 384 $\mathrm{kN}$ for Case A and $220 \mathrm{kN}$ for Case B assuming full restraints in y-direction. According to the analysis results shown in Table 2, the actual column is close to fully constrained in y-direction for both Case A and Case B. 


\section{Effect of loading eccentricities due to geometrical imperfections}

In the real structures, there are at least four possible arrangements of loading eccentricity in steel columns due to initial imperfections (Fig. 11). FE analyses were conducted to investigate the influence of different positions of loading eccentricity on the buckling resistance of steel columns. Table 4 summarizes the obtained buckling resistances. It can be seen that the buckling resistances for case EC-2 and EC-4 (the symmetric cases) are around 10\% higher than EC-1 and EC-4 (asymmetric cases).

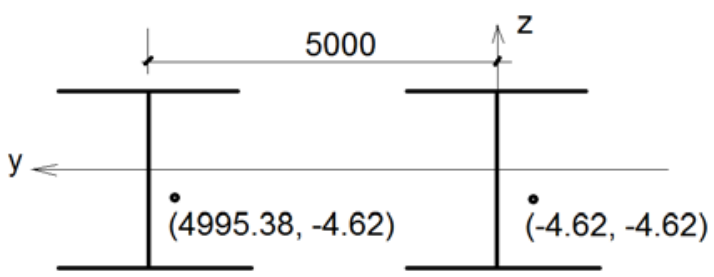

(a) Case EC-1

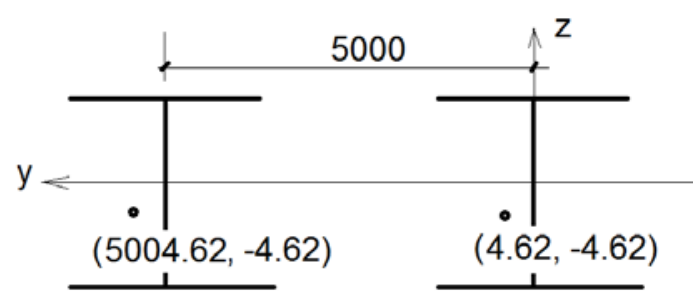

(c) Case EC-3

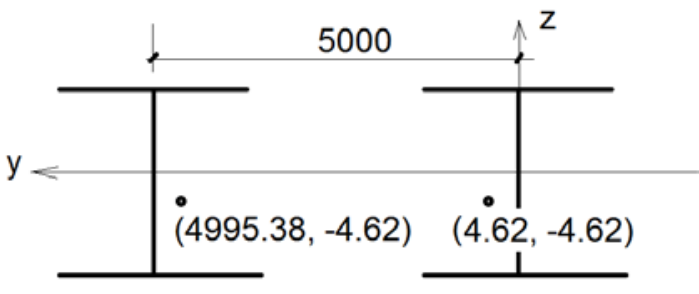

(b) Case EC-2

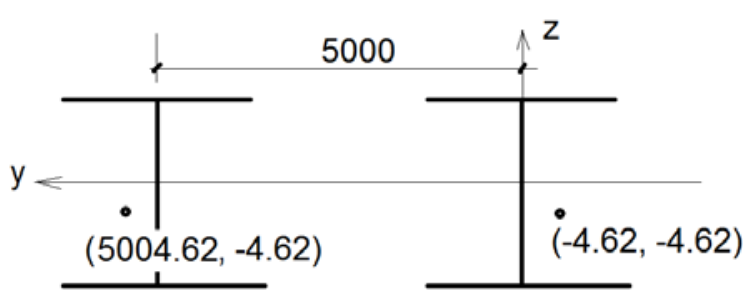

(d) Case EC-4

Fig. 11 Four configurations of loading eccentricities due to geometrical imperfections.

Table 4. Buckling resistances of steel columns for different eccentricity configuration.

\begin{tabular}{c|c|c|c}
\hline \multirow{2}{*}{$\begin{array}{c}\text { Cases of loading } \\
\text { eccentricities }\end{array}$} & \multicolumn{2}{|c|}{ Buckling resistances (kN) } & $\begin{array}{c}\text { Difference from } \\
\text { Case-EC-1 (\%) }\end{array}$ \\
\cline { 2 - 3 } & Column-R & Column-L & - \\
\hline EC-1 & 428 & 410 & 10.0 \\
\hline EC-2 & 449 & 458 & -1.0 \\
\hline EC-3 & 406 & 428 & 10.0 \\
\hline EC-4 & 450 & 458 & \\
\hline
\end{tabular}

In real steel frame structures with sandwich panels as building envelope, the position of loading eccentricities due to initial imperfection is random, and all above cases are possible for both internal and side frames. Therefore when studying the stabilization 
effects, configuration of Case EC-1 or EC-3 should be used and the lower buckling resistance of the columns should be taken as stabilized buckling resistance of studied column.

\section{Conclusions}

Two different types of FE models to simulate the steel columns supported by sandwich panels were developed in this paper and validated by the full-scale tests by HedmanPetursson. The bracing forces in self-drilling screws, the effect of connections in horizontal joints, and effects of the lateral stiffness of self-drilling screws were further studied at ambient temperature. It was found by FE analyses that the maximum force in the end fastening connections along the column is $6.1 \mathrm{kN}$ corresponding to the column buckling load. This indicates that three self-drilling screws are needed in each end connection in order to provide full stabilization on column for the studied structures. Effect of connections in horizontal joints is insignificant in the studied case for the stabilization effect of sandwich panels on steel column. The lateral stiffness of selfdrilling screw is much higher based on the European Recommendations [3] than used in the analyses and this increased the buckling resistance of studied steel column $10 \%$.

Due to the large in-plane stiffness, sandwich panels can provide full or partial constraints for steel columns against in-plane flexural buckling. The degree of constraints against buckling depends on the stiffness and strength of screw fasteners connecting the sandwich panels and steel columns. For the typical self-drilling screws with $5.5 \mathrm{~mm}$ in diameter in four corners of panels, and core thickness of steel facings $0.52 \mathrm{~mm}$, the lateral shear stiffness is usually around or greater than $1000 \mathrm{~N} / \mathrm{mm}$. In this study, the steel columns HEA120 supported by sandwich panels can achieve full constraints against in-plane flexural buckling (the minor axis buckling). However, the shear force developed in the screw fasteners requires at least three screws in the corners of the sandwich panels near both ends of steel columns in order to fulfill the strength requirement.

The configuration of loading eccentricities has influence on the buckling resistances of steel columns. Generally speaking, the buckling resistances of the symmetric cases of loading eccentricities are 10 percent higher than the asymmetric cases, for small eccentric cases. In studying the stabilization effect, the configuration for asymmetric loading eccentricity should be taken into use.

\section{References}

[1] Cooke, G.M.E. Stability of lightweight structural sandwich panels exposed to fire. Second International Workshop on Structure in Fire, March, 2002, Christchurch, UK.

[2] EASIE. Ensuring advancement in sandwich construction through innovation and exploitation. Project final report, 2013. Available at: http://www.ppaeurope.eu/db/docs/EASIE-FinalReport-Part2_for-publication.pdf. 
[3] ECCS/CIB. European recommendations on the stabilization of steel structures by sandwich panels. Publication 379, ECCS TC7 and CIB W056, 20113.

[4] Hedman-Petursson, E. Column buckling with restraints from sandwich wall elements. Doctoral thesis, Steel Structure Division, Department of Civil and Mining Engineering. Lulea, Sweden, 2001.

[5] LSTC. Ls-Dyna R9.0 keyword manual. Livermore Software Technology Corporation, 2016.

[6] Misiek, T., Käpplein, S., Saal, H. and Ummenhofer, T. Stabilization of beams by sandwich panels -Lateral and torsional restraint. EuroSteel, August 31-September 2, 2011. Budapest, Hungary.

[7] SFS EN1993-1-1. Eurocode 3: Design of steel structures -Part 1.1: General rules and rules for buildings. May 2005.

Zhongcheng Ma, Jarmo Havula

Sheet Metal Center, School of Technology

Häme University of Applied Sciences

Visakaarre 9, 13100 Hämeenlinna

Finland

zhongcheng.ma@hamk.fi, jarmo.havula@hamk.fi

Markku Heinisuo

Tampere University of Technology

Laboratory of Civil Engineering

P.O.Box 600, FI-33101 Tampere

Finland

markku.heinisuo@tut.fi 